\title{
Metal-mediated aminocatalysis provides mild conditions: Enantioselective Michael addition mediated by primary amino catalysts and alkali-metal ions
}

\author{
Matthias Leven, Jörg M. Neudörf|§ and Bernd Goldfuss*
}

\section{Full Research Paper}

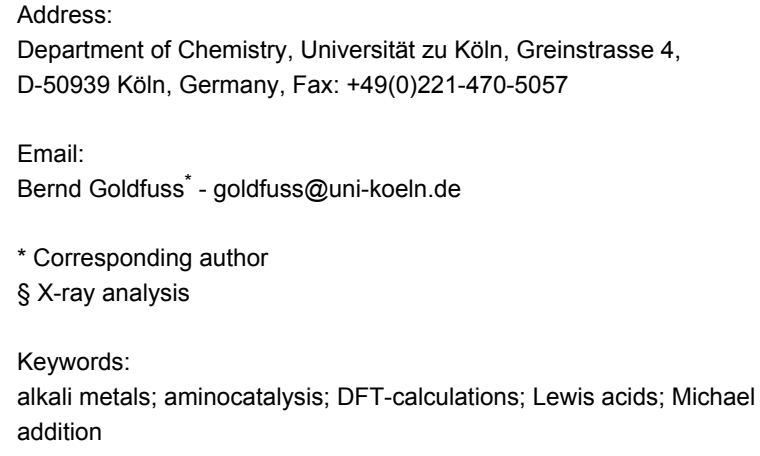

\author{
Beilstein J. Org. Chem. 2013, 9, 155-165. \\ doi:10.3762/bjoc.9.18 \\ Received: 15 November 2012 \\ Accepted: 18 December 2012 \\ Published: 23 January 2013 \\ Associate Editor: M. Rueping \\ (c) 2013 Leven et al; licensee Beilstein-Institut. \\ License and terms: see end of document.
}

\begin{abstract}
Four catalysts based on new amides of chiral 1,2-diamines and 2-sulfobenzoic acid have been developed. The alkali-metal salts of these betaine-like amides are able to form imines with enones, which are activated by Lewis acid interaction for nucleophilic attack by 4-hydroxycoumarin. The addition of 4-hydroxycoumarin to enones gives ee's up to $83 \%$ and almost quantitative yields in many cases. This novel type of catalysis provides an effective alternative to conventional primary amino catalysis were strong acid additives are essential components.
\end{abstract}

\section{Introduction}

Organocatalysis based on primary or secondary amines enables a myriad of enantioselective transformations, e.g., with aromatic or aliphatic enones [1]. There are many approaches employing protonated derivatives of chinchona alkaloids [2-5], amino acid derivatives, and chiral 1,2-diamines, which provide excellent yields and enantioselectivities. Among the most famous examples are Mac Millan's secondary-amine-based catalysts [6] or 9-amino-9-deoxy-epihydroquinine salts used by Jørgensen et al. [7,8].

Another growing field of catalysis is metal-promoted organocatalysis, which is closely related to tandem reactions of metal- and organocatalysis [9-13]. In most cases, transition or rare-earth metals are employed as Lewis acids in order to acti- 
vate electrophilic compounds to react with substrates that are directly bonded to an organic catalyst [9-13]. An example is the enamine-metal Lewis acid bifunctional catalysis for asymmetric direct aldol reaction, which is mediated by copper ions and amino acid derivatives [14] or enamine nucleophilic addition to palladium $\pi$-allyl electrophiles [15-17].

We report the development of new catalysts based on chiral 1,2diamines and present their application in the asymmetric addition of 4-hydroxycoumarin (1) to prochiral $\alpha, \beta$-unsaturated ketones. Instead of acid additives, which sometimes lead to decomposition of sensitive components [18], alkali-metal ions are employed as very mild Lewis acids (Scheme 1).

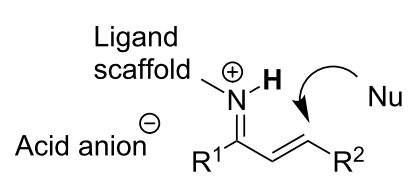

Protonation by Brønstedt acid

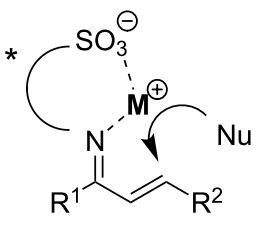

Metal-mediated aminocatalysis
Scheme 1: Activation of amine-bonded Michael acceptors by protonation versus Lewis acid interaction.

The activation of Michael acceptors by iminium ions enables asymmetric additions of 4-hydroxycoumarins to $\alpha, \beta$-unsaturated ketones (Scheme 2) [19-27].

There is a wide spread of 4-hydroxycoumarins in pharmaceuticals such as anticoagulants and substances that inhibit HIV or malaria $[28,29]$. Among the most prominent chiral 4-hydroxycoumarins is warfarin, which works as a vitamin $\mathrm{K}$ antagonist, and the dissimilar activity of the enantiomers is well documented in the literature [30-32]. The organocatalytic synthesis of warfarin has already been tested with several organocatalysts. Diphenylglycinol derivatives and derivatives of 1,2-diphenylethane-1,2-diamine provided good yields and ee's in the range of $80 \%$ [19-27]. Other attempts employing chinchona alkaloids provided ee's higher than $90 \%$ [24].

\section{Results and Discussion}

The newly developed catalysts are derived from $C_{2}$-symmetric chiral diamines $\mathbf{2}$ and $\mathbf{3}$ and 2-sulfobenzoic acid by formation of a carboxylic amide (Scheme 3 ). The active site consists of a primary amino group and a sulfonic acid group, which can form chelates with cations. The sulfonic acid derivatives are accessible through efficient transformations of diamines with 2-sulfobenzoic anhydrides 4 (Scheme 3).

Typical yields of the transformation (Scheme 3) are 83\% for 5 and $75 \%$ for 7 . Side-products such as the diamides are rarely formed if an immediate in situ precipitation of the desired product is achieved. The structural chelate character of the spontaneously formed salts can also be observed in the crystallographic structure of 5 (Figure 1). A characteristic detail in the $\mathrm{X}$-ray crystallographic structure of $\mathbf{5}$ is the intramolecular hydrogen bond between $\mathrm{H} 10$ and $\mathrm{O} 3$ (distance: $2.283 \AA$ ) in Figure 1, which restricts the conformation of the 2-sulfobenzoic moiety.

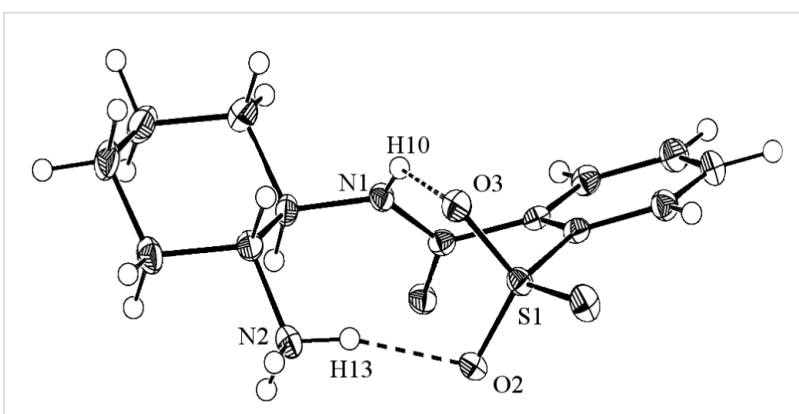

Figure 1: X-ray crystallographic structure of 5 . The conformation of the 2-sulfobenzoic moiety is fixed by hydrogen bonds. The distance $\mathrm{H} 10 \cdots \mathrm{O} 3$ is $2.283 \AA$, the distance $\mathrm{H} 13 \cdots \mathrm{O} 2$ is $1.920 \AA$. (distance N1-O3: $2.865 \AA$, distance N2-O2: $2.822 \AA$, ellipsoids: $50 \%$ probability)

It was found that the solubility of each precatalyst shown in Scheme 3, which is essential for the application in catalysis, depends strongly on the specific substituents. The 1,2diaminocyclohexane-based precatalyst $\mathbf{5}$ is soluble in water but hardly in methanol or THF if no DMSO is added. Thus, the application of this compound in catalysis is limited by the range of appropriate solvents. Bromine derivative 6, which is based on 1,2-diaminocyclohexane as well, exhibits a markedly higher<smiles>[R]C=CC([R])=O</smiles> 


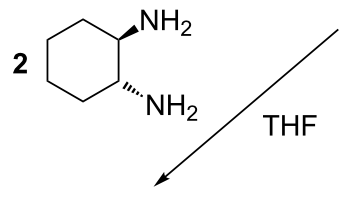<smiles>N[C@@H]1CCCCC1NC(=O)c1ccccc1[O-]</smiles>

5

precatalysts<smiles>N[C@H]1CCCCC1NC(=O)c1c([O-])c(Br)c(Br)c(Br)c1Br</smiles>

6<smiles>[R]c1c([R])c([R])c2oc(=O)oc2c1[R]</smiles>

4

$\mathrm{R}^{1-4}=\mathrm{H}$ or $\mathrm{Br}$<smiles>COc1ccc(C(N)C(N)c2ccc(OC)cc2)cc1</smiles><smiles>COc1ccc(C(NC(=O)c2ccccc2S(=O)(=O)[O-])[C@H]([NH-])c2ccc(OC)cc2)cc1</smiles><smiles>COc1ccc(C(NC(=O)c2c([O-])c(Br)c(Br)c(Br)c2Br)c2ccc(OC)cc2)cc1</smiles>

Scheme 3: Precatalysts 5-8 and synthesis from chiral 1,2-diamines and 2-sulfobenzoic anhydrides.

solubility in THF and can also be dissolved in mixtures of alcohols and DCM. Precatalysts 7 and 8 are derived from 1,2diphenylethane-1,2-diamine and the solubility of these substances in organic solvents is significantly higher than that of 5 or $\mathbf{6}$. This effect could be due to the methoxy groups, and $\mathbf{8}$ can easily be applied in THF or chloroform.

The first step in finding a well-performing catalytic active system was to find a catalyst-metal combination that generates satisfying yields. The idea was to choose a Lewis acid that is strong enough to activate the imine preformed by the catalyst and the Michael system, so that the nucleophilic attack shown in Scheme 1 occurs. On the other hand Lewis acids that are too strong could inhibit the formation of the imine by complexation of the primary amino group. The most promising counter ions are expected to be from the first group of the periodic table of elements, and test reactions were carried out by employing catalyst 5 and 7 with benzylideneacetone (9) and cyclohex-2-enone (10) (Figure 2) as substrates (Table 1). It was found that very mild conditions prevail under catalytic conditions if alkali metals are used as Lewis acids, since the $\mathrm{pH}$ value of the<smiles>CC(=O)/C=C/c1ccccc1</smiles>

9<smiles>O=C1C=CCCC1</smiles>

10

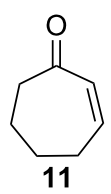

Figure 2: Michael acceptors employed as substrates in the nucleophilic addition of 4-hydroxycoumarin (1).

dissolved catalyst is in the range of 9 (see Experimental section for details).

The application of catalysts 5 and 7 (Table 1) indicates that lithium cations are the most suitable counterions for the activation of the Michael acceptor, with $94 \%$ isolated yield (Table 1, entries 3 and 4). Sodium and potassium ions are slightly less sufficient with yields up to $72 \%$ (sodium, Table 1 , entry 5) or $74 \%$ (potassium, Table 1 , entry 10). Zinc does almost not work at all (yields are $5 \%$ or less, Table 1, entries 7 and 8 ). The reason for the low yields when using zinc may be 
Table 1: Screening of 5 and 7 with different metal counter ions. ${ }^{a}$

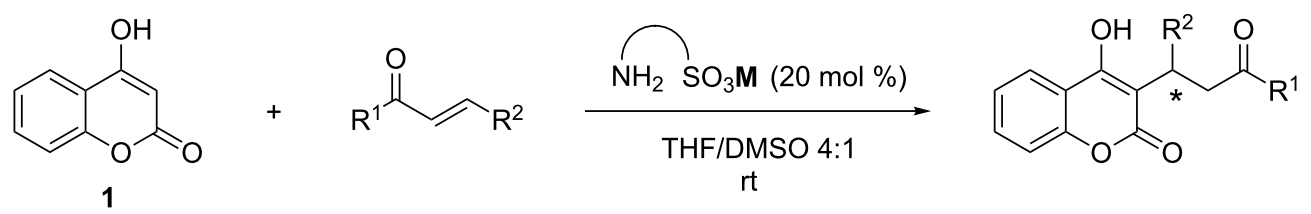

\begin{tabular}{|c|c|c|c|c|c|}
\hline Entry & Catalyst & M & Time $[d]^{b}$ & Yield [\%] & ee $[\%]^{d}$ \\
\hline 1 & 5 & $\mathrm{H}$ & 3 & $<5$ & - \\
\hline 2 & 7 & $\mathrm{H}$ & 3 & $<5$ & - \\
\hline 3 & 5 & $\mathrm{Li}$ & 2 & 94 & 44 \\
\hline 4 & 7 & $\mathrm{Li}$ & 2 & 94 & 15 \\
\hline 5 & 5 & $\mathrm{Na}$ & 3 & 72 & 47 \\
\hline 6 & 7 & $\mathrm{Na}$ & 3 & 7 & 26 \\
\hline 7 & 5 & $\mathrm{Zn}$ & 4 & 0 & - \\
\hline 8 & 7 & $\mathrm{Zn}$ & 4 & 5 & 21 \\
\hline 9 & 5 & $\mathrm{~K}$ & 2 & 62 & 36 \\
\hline 10 & 7 & $\mathrm{~K}$ & 2 & 74 & 28 \\
\hline $11^{\mathrm{e}}$ & 5 & $\mathrm{Na}$ & 3 & 45 & 47 \\
\hline $12^{\mathrm{e}}$ & 7 & $\mathrm{Na}$ & 3 & 99 & 16 \\
\hline
\end{tabular}

${ }^{a} A l l$ reactions were carried out with $20 \mathrm{~mol} \%$ catalyst in abs. THF/DMSO 4:1 at room temperature. Unless otherwise specified the substrate was benzylideneacetone (9). ${ }^{b}$ Conversion controlled by TLC. CIsolated yield. dee determined by chiral HPLC. eSubstrate was cyclohex-2-enone (10).

that the Lewis acidity is too strong, which could lead to formation of inactive complexes of the catalyst. Since hydrogen $(\mathrm{M}=\mathrm{H})$ does not provide any isolatable conversions at all (Table 1, entries 1 and 2), it seems to be clear that the zwitterionic chelate shown in Figure 1 is too inert to form imines with carbonylic compounds. The choice of alkali metal does not affect the ee very markedly and the ee's obtained in Table 1 are in the moderate range (up to $47 \%$ ).

In order to elucidate if Lewis acid free imines could also react as Michael acceptors, experiments employing triethylammonium salts of the catalysts $\mathbf{5}$ and $\mathbf{7}(\mathrm{pH} \mathrm{9)}$ ) were performed, and no conversions could be detected in all cases.

Because lithium was identified as the most appropriate alkalimetal ion for application in the catalysis (Table 1), the following experiments were carried out with lithium salts of catalysts 5-8. In order to improve the enantioselectivities, solvent related conditions were varied systematically so that reactions could be carried out at low temperatures. 4-Hydroxycoumarin and the catalysts require very polar solvents as additives, e.g., DMSO, which precipitate at low temperatures. Alcohols employed as antifreezing additives at temperatures of $-20{ }^{\circ} \mathrm{C}$ or as pure solvents effected decreasing ee's in the most cases. Thus, the range of suitable solvents was strongly limited by the low solubility of all compounds in indifferent liquids. Nevertheless, the ee could be improved up to $83 \%$ (Table 2, entry 7).
The results shown in Table 2 indicate that the catalysts $\mathbf{7}$ and $\mathbf{8}$ based on 1,2-diphenylethane-1,2-diamine perform indeed better than 5 and 6, based on trans-1,2-diaminocyclohexane: The highest ee that could be obtained by $\mathbf{8}$ is $83 \%$ whereas the transdiaminocyclohexane derivatives could only reach up to $47 \%$ ee (Table 1, entry 5). There is a strong preference for 7 to produce higher ee's if cyclic enones are used, whereas diaminocyclohexane derivatives perform better with the acyclic trans-enone 9 (Table 1 , entry 4 versus Table 2, entry 1 ). There is also a significantly stronger chiral induction for the bromine derivative 8 derived from 7 (ee increases from $72 \%$ to $83 \%$, Table 2 , entries 1 and 7).

\section{The origin of enantioselectivity}

In order to obtain a mechanistic insight into the newly designed catalysis and the origin of enantioselectivity, DFT calculations on the enantio-determining transition states were performed by employing the nonempirical TPSS-functional and BP86. Two possible pathways were found computationally (pathway $\mathbf{A}, \mathbf{B}$, Scheme 4).

The first essential step in the catalytic process is the formation of the imine intermediate $\mathbf{1 2}$ from the catalyst and the Michael substrate 10 (Scheme 4) [6]. Formation of $\mathbf{1 2}$ by catalyst 8 (Figure 2) under in situ conditions could also be proven by ESIMS spectrometry $(\mathrm{m} / \mathrm{z}=855.1$, see Supporting Information File 1 for details) to underpin an activation process by the imine-lithium complex. The addition of 4-hydroxycoumarin to 
Table 2: Screening of catalysts 5, 6, 7, 8 under various conditions with different substrates. ${ }^{a, b}$

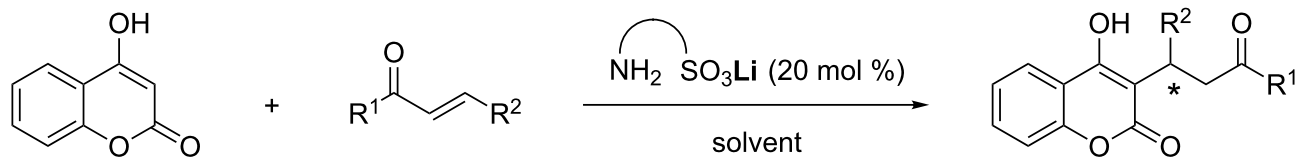

1

\begin{tabular}{|c|c|c|c|c|c|c|c|}
\hline Entry & Substrate ${ }^{a}$ & Catalyst $^{\mathrm{b}}$ & Solvent ${ }^{c}$ & $T\left[{ }^{\circ} \mathrm{C}\right]$ & Time [d] & Yield [\%] $^{d}$ & ee $[\%]^{\mathrm{e}}$ \\
\hline 1 & 10 & 7 & 1 & 0 & 3 & 99 & 72 \\
\hline 2 & 10 & 7 & 2 & -20 & 4 & 61 & 66 \\
\hline 3 & 10 & 7 & 3 & 0 & 3 & 99 & 64 \\
\hline 4 & 10 & 7 & 4 & 0 & 3 & 99 & 63 \\
\hline 5 & 10 & 5 & 1 & 20 & 2 & 46 & 17 \\
\hline 6 & 10 & 7 & 1 & 20 & 2 & 99 & 68 \\
\hline 7 & 10 & 8 & 1 & 0 & 2 & 99 & 83 \\
\hline 8 & 9 & 6 & 1 & 20 & 2 & 99 & 42 \\
\hline 9 & 11 & 8 & 1 & 0 & 2 & 99 & 60 \\
\hline 10 & 11 & 7 & 1 & 0 & 2 & 99 & 51 \\
\hline 11 & 10 & 6 & 1 & 20 & 2 & 77 & 23 \\
\hline 12 & 10 & 8 & 1 & 20 & 2 & 61 & 43 \\
\hline 13 & 11 & 5 & 1 & 20 & 2 & 44 & 13 \\
\hline 14 & 11 & 6 & 1 & 20 & 2 & 63 & 30 \\
\hline
\end{tabular}

${ }^{\mathrm{a}} \mathbf{1 0}=$ Cyclohex-2-enone; $\mathbf{9}$ = benzylideneacetone; $\mathbf{1 1}$ = cyclohept-2-enone. ${ }^{\mathrm{b}}$ The metal counter ion is lithium. ${ }^{\mathrm{C}}$ Solvents: 1 = abs. THF/DMSO 4:1; 2 = abs. THF/ethylene glycol 4:1; 3 = dioxane; 4 = isopropanol. ${ }^{\mathrm{d}}$ Isolated yield. ${ }^{\mathrm{e}}$ ee determined by chiral HPLC.

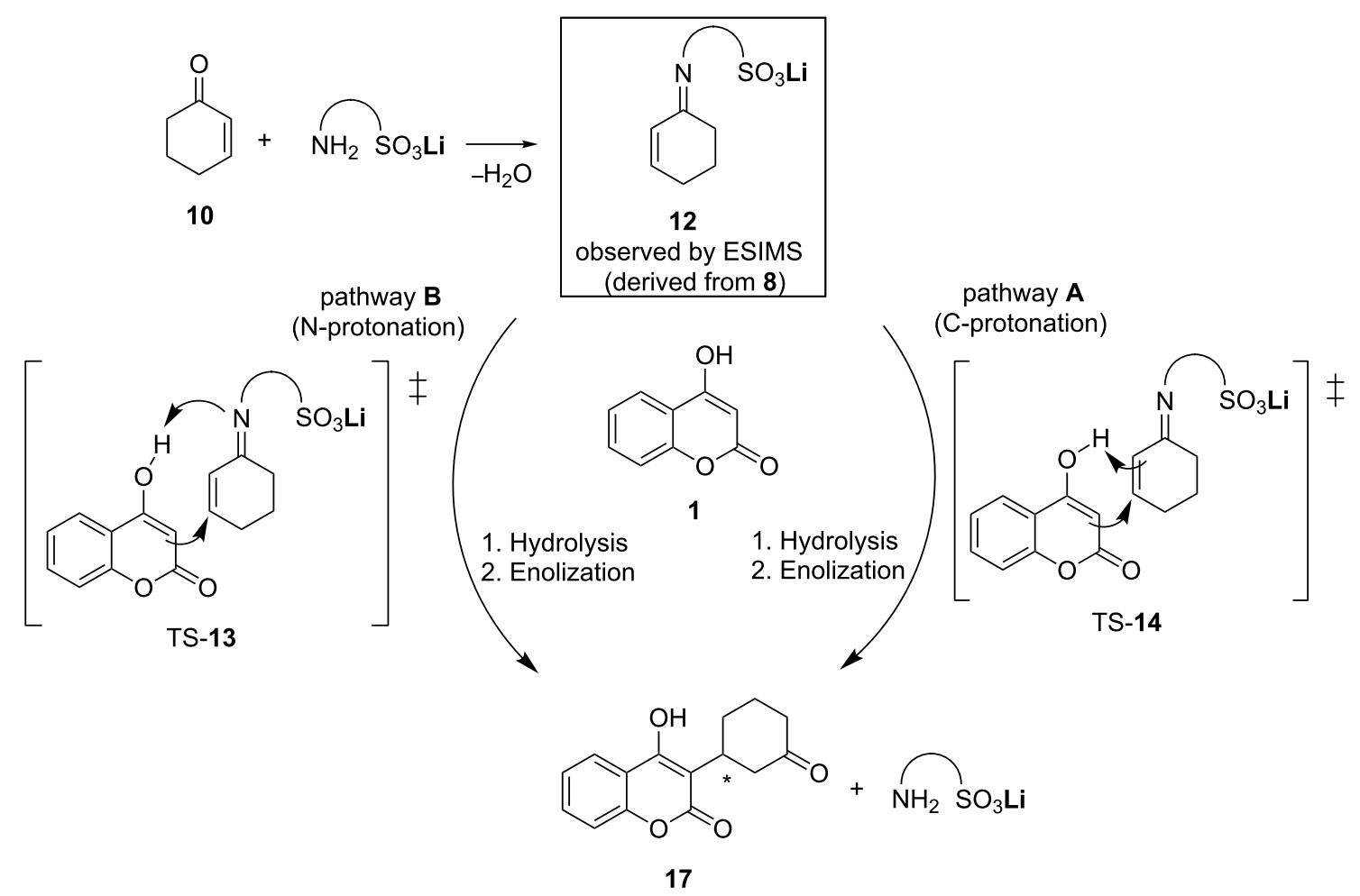

Scheme 4: Computationally analyzed pathways A (C-protonation), and B (N-protonation), arising from the addition of 4-hydroxycoumarin to cyclohexenone. 
the activated Michael system 12 could now occur along two slightly different mechanistic pathways (A, B, Scheme 4) including the enantio-determining transition states corresponding to TS-13 or TS-14. Both pathways require the formation of a carbon-carbon bond and the dissociation of the oxygen-hydrogen bond of the hydroxy group, exhibited by the 4-hydroxycoumarin. The only difference lies in the migration of the shifted proton to carbon (pathway A) or nitrogen (pathway B).

Both reaction paths considered in Scheme 5 are of concerted character, and ionic intermediates of stepwise additions are not stationary points on the potential energy surface. The relative energies for the two possible pathways A, B (Scheme 5) suggest that the reaction path $\mathbf{A}$, involving C-protonation in the enantiodetermining step, is clearly favored. The enantio-determining transition states TS-13 and TS-14 differ by $10.8 \mathrm{kcal} / \mathrm{mol}$, whereby TS-14 is the favored. Intermediate $\mathbf{1 6}$ is $7.2 \mathrm{kcal}$ lower in energy than 15. Hence, it is apparent that the enantio-determining step of the addition to the Michael acceptor is TS-14. Another point of interest in the mechanistic study is how enantioselectivity can be predicted [33].

In order to elucidate the mechanistic process, all accessible enantio-determining transition structures corresponding to TS-14 were computed for the addition of 4-hydroxycoumarin to cyclohexenone employing ligand $\mathbf{8}$. There are two conformational degrees of freedom (Figure 3) giving rise to eight

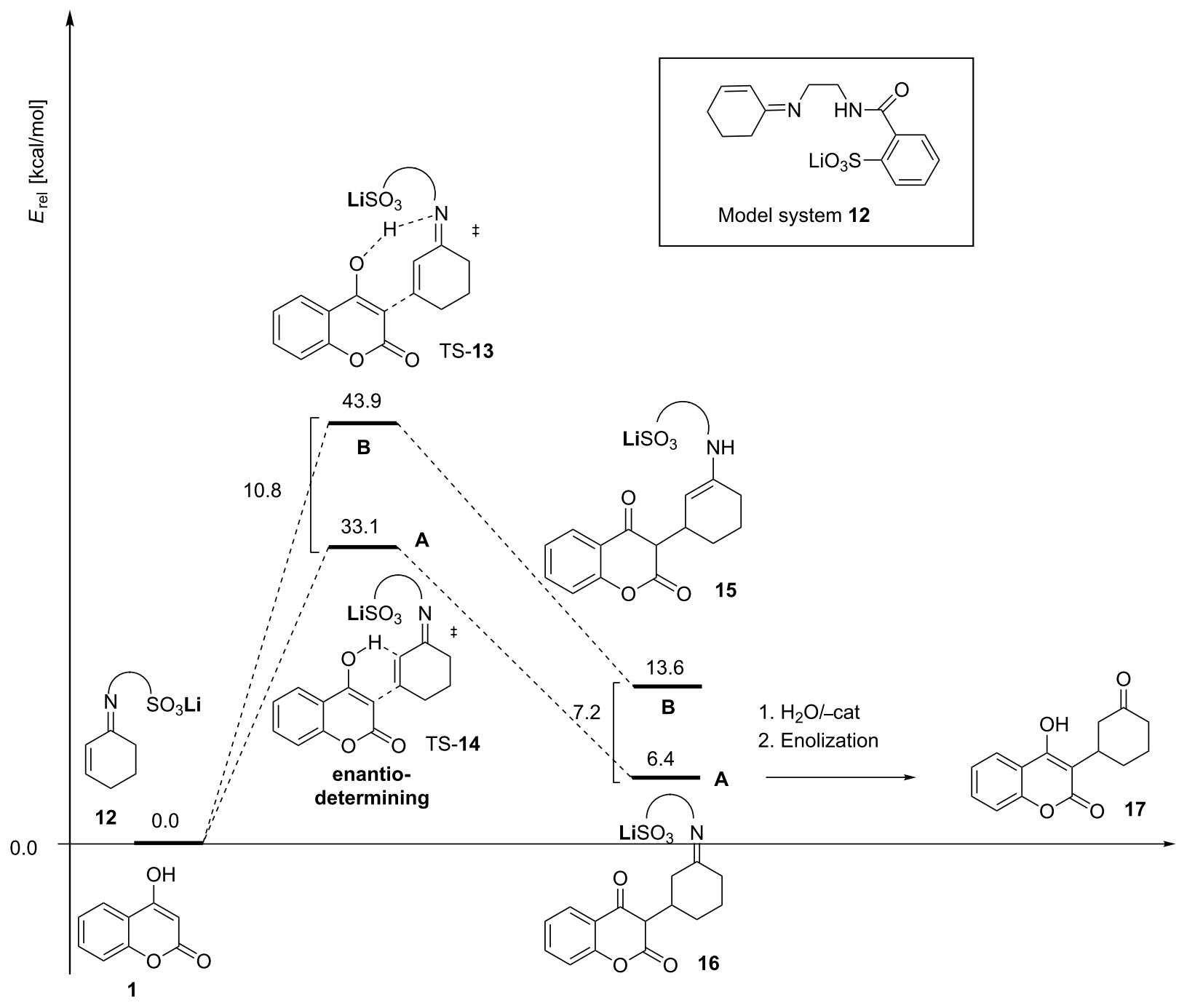

Scheme 5: Computed energy profile for reaction path A (C-protonation) and B (N-protonation) corresponding to a model system 12 BP86/SVP+ZPE. The C-protonation route includes the more favored enantio-determining transition state TS-14. Hydrolysis and enolization of intermediates 15 and 16 will subsequently occur under in situ conditions. 

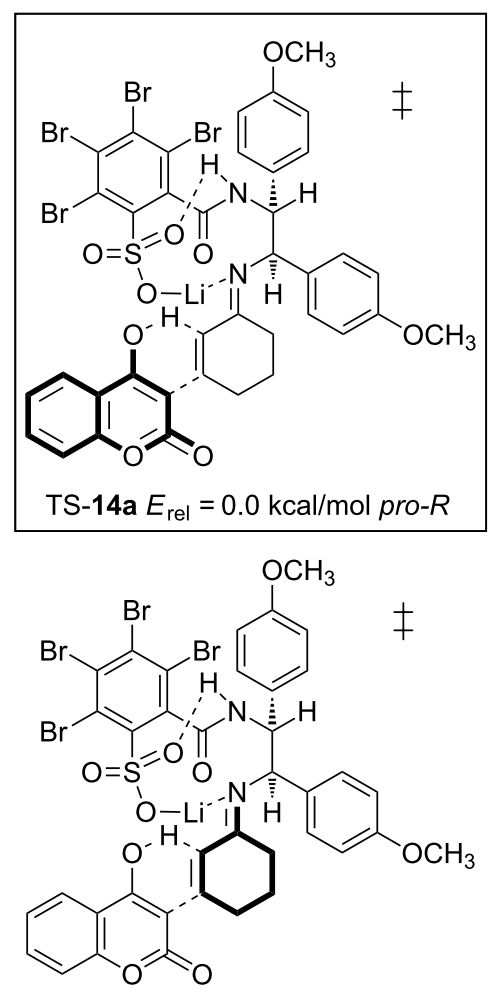

TS-14c $E_{\text {rel }}=3.6(1.4) \mathrm{kcal} / \mathrm{mol}$ pro-S

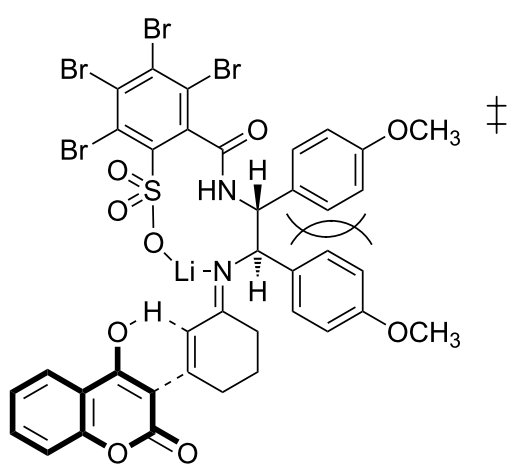

TS-14e $E_{\text {rel }}=14.3(14.0) \mathrm{kcal} / \mathrm{mol}$ pro- $R$

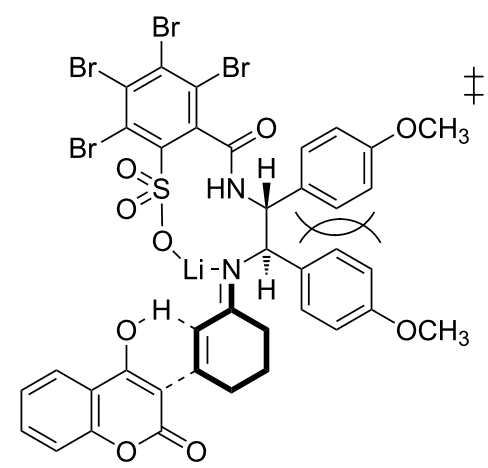

$\mathrm{TS}-14 \mathrm{~g} E_{\mathrm{rel}}=2.3(2.9) \mathrm{kcal} / \mathrm{mol}$ pro-S

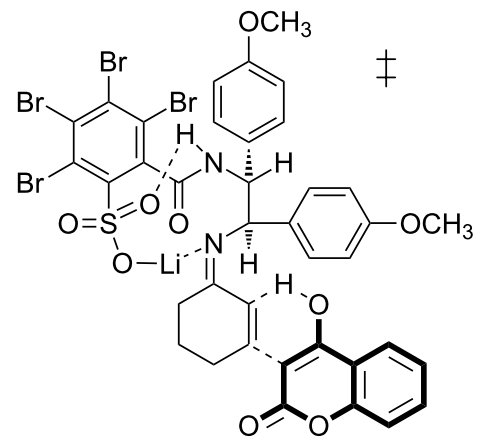

TS-14b $E_{\mathrm{rel}}=2.6(1.5) \mathrm{kcal} / \mathrm{mol}$ pro-S

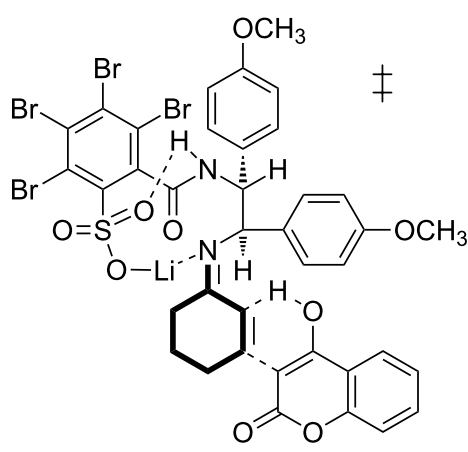

TS-14d $E_{\text {rel }}=0.1(0.4) \mathrm{kcal} / \mathrm{mol}$ pro- $R$

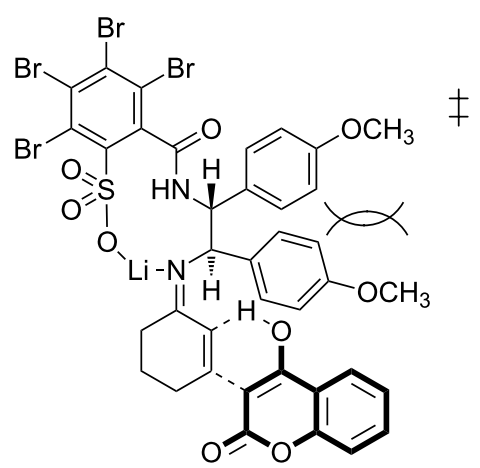

TS-14f $E_{\text {rel }}=16.4(16.7) \mathrm{kcal} / \mathrm{mol}$ pro-S

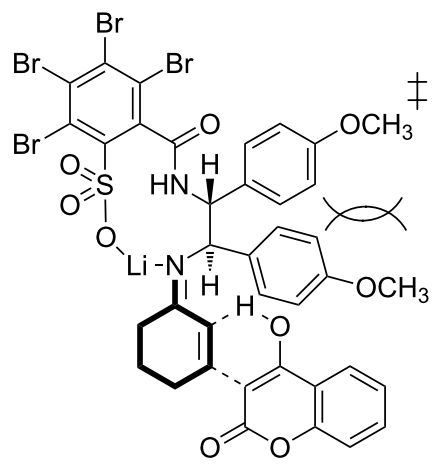

TS-14h $E_{\text {rel }}=20.3(20.4) \mathrm{kcal} / \mathrm{mol}$ pro- $R$ 
structures (four pro- $R$ and four pro-S-configurations), which have to be compared (Figure 3).

The transition structures shown in Figure 3 were initially calculated with the BP86 functional (relative energies in parenthesis). In order to ensure the results and increase the accuracy, structures $\mathbf{1 4} \mathbf{a}-\mathbf{h}$ were re-optimized employing the nonempirical TPSS functional. Relative energies in Figure 3 suggest that transition structure TS-14a is the most favored by $2.3 \mathrm{kcal} / \mathrm{mol}$ compared to the lowest competing TS in pro-S-configuration, TS-14g. Since TS-14a exhibits pro- $R$-configuration, the $(R)$ enantiomer of 17 should be generated in majority. The experimentally favored enantiomer is indeed $(R)$-configured with $83 \%$ ee (Table 2, entry 7). This value is in good agreement with an energetic differentiation of the enantio-determining transition states of $2.3 \mathrm{kcal} / \mathrm{mol}$ although no solvent dependent effects are taken into account [33]. (Solvent corrections to the single-point energies lead to similar results, which are given in Supporting Information File 1). An interesting detail concerning the conformational degrees of freedom in transition structures TS-14 is the more favored alignment of the 2-sulfobenzoic moiety according to TS-14a-d (Figure 3 and Figure 4). This conformation allows the formation of an intramolecular bond between the lithium ion and the nitrogen of the amide group. A similar structural property is found in the X-ray crystallographic structure of compound 5 (Figure 1). The same conformation of the 2-sulfobenzoic moiety is fixed by two intramolecular hydrogen bonds. There is also a conspicuous reason for the relatively high energies of the transition states 14e-h: anisyl groups in TS-14e-h are forced into a disfavored syn-conformation, which leads to steric repulsion (Figure 4).

\section{Conclusion}

Four chiral enantiopure precatalysts based on chiral trans-1,2diamines have been developed. These precatalysts, 5, 6, 7 and $\mathbf{8}$, exhibit a primary amino group, which is protonated by a neighboring sulfonic acid group. The formed zwitterionic salts can be easily transformed to alkali-metal salts, which are able to form imine complexes with prochiral $\alpha, \beta$-unsaturated ketones, which could be detected by ESIMS spectrometry in an exemplary case. It was found that the Lewis acidities of the alkali metal ions are strong enough to activate the imine homologous Michael systems for nucleophilic addition of 4-hydroxycoumarin in an efficient way since conversions are often in the
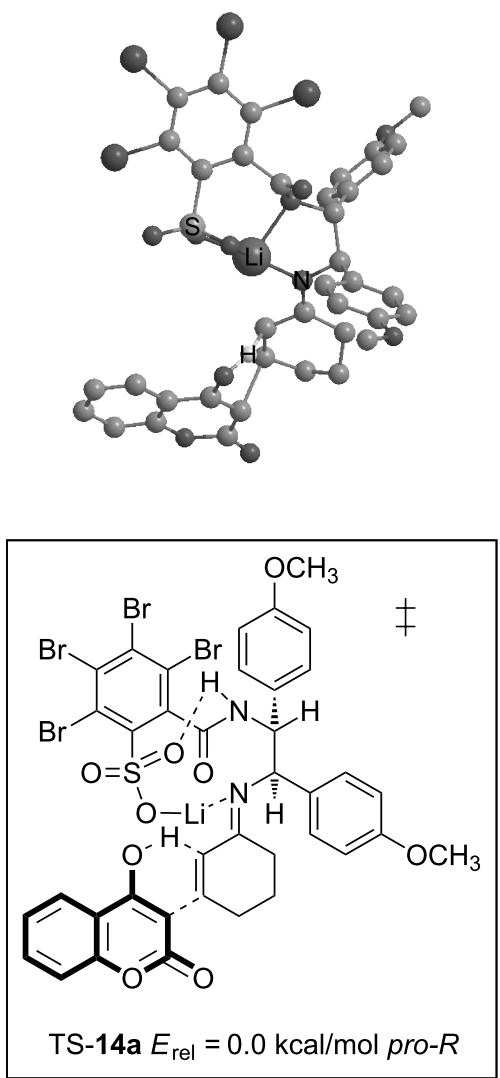
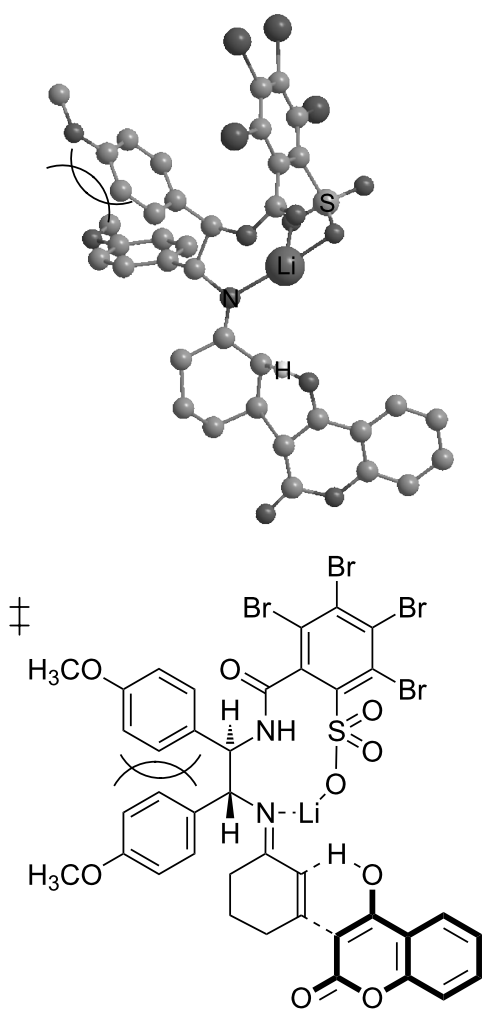

TS-14g $E_{\text {rel }}=2.3 \mathrm{kcal} / \mathrm{mol}$ pro-S

Figure 4: The competing enantio-determining transition structures TS-14a and TS-14g. The reason for the destabilization of $\mathbf{1 4 g}$ (most stable pro-S) is the steric repulsion of anisyl groups in the backbone (TPSS/SVP+ZPE). 
quantitative range. Furthermore, the catalysts provide very mild $\mathrm{pH}$ conditions, since the $\mathrm{pH}$ values are in the range of 9 . This is very unusual, since ordinary primary amine catalysts require strong acids as additives, which can destroy sensitive components [18]. Attempts to employ the metal-free zwitterionic salts did not succeed for this type of catalyst. The enantiomeric excesses that could be achieved by the use of 5-8 were moderate to good up to $83 \%$, and the origin of chiral induction could be rationalized by means of DFT calculations. It was found that there is one conformation of the enantio-determining transition structure TS-14 that dominates sufficiently because steric repulsion of the anisyl groups in the ligand backbone is minimized.

\section{Experimental General}

Solvents used in chemical conversions were dried by standard methods and distilled under argon prior to use. The enantiomeric excesses of the chiral 4-hydroxycumarin derivatives were determined by chiral HPLC. Unless otherwise specified, we employed the La Chrome elite unit from Hitachi together with the chiral column Chiracel AD-H in $25 \mathrm{~cm}$ length. The flow was adjusted to $0.8 \mathrm{~mL} / \mathrm{min}$, the pressure was 32 bar and the detected wavelength $\lambda=240 \mathrm{~nm}$. The eluent consisted of $80 \%$ hexanes and $20 \%$ isopropanol. The enantiomers of the chiral compounds were identified by reference spectra of racemates and literature data [23].

Synthesis of compound 5. The 2-sulfobenzoic anhydride 4 , $\mathrm{R}^{1-4}=\mathrm{H}$ (1.751 mmol, $\left.322 \mathrm{mg}\right)$ was dissolved in $15 \mathrm{~mL}$ THF. The mixture was cooled to $0{ }^{\circ} \mathrm{C}$ and $(1 R, 2 R)$-1,2-diaminocyclohexane $(1.751 \mathrm{mmol}, 200 \mathrm{mg}$ ) was added in $5 \mathrm{~mL}$ THF. The solution was soon thickened by white precipitate, and the suspension was stirred for $24 \mathrm{~h}$. The solvent was removed in vacuum, and the white solid was purified by crystallization from methanol. Yield: $434 \mathrm{mg}$, crude, $83 \%$ and $307 \mathrm{mg}$, pure, $59 \%$. Mp $344{ }^{\circ} \mathrm{C}$ (decomposition); IR (nujol) v: 2970, 1665, 1596, 1251, 1141; ${ }^{1} \mathrm{H}$ NMR (300 MHz, D $\left.2 \mathrm{O}\right)$ 0.88-1.14 (4H, m), 1.47-1.56 (2H, m), 1.74-1.98 (2H, m), 2.35-2.54 $(1 \mathrm{H}, \mathrm{m}), 3.38-3.57(1 \mathrm{H}, \mathrm{m}), 7.29-7.42(1 \mathrm{H}, \mathrm{m}), 7.40-7.61$ $(2 \mathrm{H}, \mathrm{m}), 7.74-7.91(1 \mathrm{H}, \mathrm{m}) ;{ }^{13} \mathrm{C}$ NMR $\left(75.5 \mathrm{MHz}, \mathrm{D}_{2} \mathrm{O}\right) 24.25$, 24.50, 31.21, 33.07, 53.53, 56.57, 127.12, 128.28, 130.13, 131.46, 133.79, 139.07, 174.24; HRMS-ESI $(m / z):[\mathrm{M}+\mathrm{Na}]^{+}$ calcd for $\mathrm{C}_{13} \mathrm{H}_{18} \mathrm{~N}_{2} \mathrm{NaO}_{4} \mathrm{~S}$, 321.0879; found, 321.0882; X-ray crystal data: $\mathrm{C}_{13} \mathrm{H}_{18} \mathrm{~N}_{2} \mathrm{O}_{4} \mathrm{~S}, \mathrm{M}=298.35 \mathrm{~g} / \mathrm{mol}$, space group: $P 2{ }_{1} 2{ }_{1}{ }_{1}, a=8.4485(2) \AA, b=12.1533(4) \AA, c=13.6221(5) \AA$, $V=1398.68(8) \AA^{3}, Z=4, \rho=1.417 \mathrm{~g} / \mathrm{mL}, T=100(2) \mathrm{K}$, $\lambda=0.71073 \AA, \mu=0.246 \mathrm{~mm}^{-1}$, reflections: 3055 , observed: $2842(\mathrm{I}>2 \sigma(\mathrm{I}))$, parameters refined: 197, R1 $=0.0259,(\mathrm{I}>2 \sigma(\mathrm{I}))$ $\mathrm{wR} 2=0.0621, \mathrm{GOF}=1.081$, all hydrogen atoms fixed in an ideal position, nitrogen-bonded hydrogen refined. CCDC
872757 contains the supplementary crystallographic data for this paper. These data can be obtained free of charge from The Cambridge Crystallographic Data Centre via http:// www.ccdc.cam.ac.uk/data_request/cif.

Synthesis of compound 6. The 2-sulfobenzoic anhydride 4, $\mathrm{R}^{1-4}=\mathrm{Br}(0.918 \mathrm{mmol}, 459 \mathrm{mg})$ was dissolved in $7 \mathrm{~mL}$ THF. The mixture was cooled to $0{ }^{\circ} \mathrm{C}$ and $(1 R, 2 R)$-1,2-diaminocyclohexane $(0.918 \mathrm{mmol}, 105 \mathrm{mg})$ was added in $5 \mathrm{~mL}$ THF. The solution was soon thickened by grey precipitate, and the suspension was stirred for $24 \mathrm{~h}$. The solvent was removed in vacuum, and the grey solid was purified by crystallization from methanol. Yield: $510 \mathrm{mg}, 90 \%$. Mp $348^{\circ} \mathrm{C}$ (decomposition); IR (nujol) v: 2953, 2854, 1649, 1539, 1456, 1377, 1199, 1086; ${ }^{1} \mathrm{H}$ NMR (300 MHz, DMSO-d 6 ) 1.23-1.47 (4H, m), 1.60-1.80 $(2 \mathrm{H}, \mathrm{m}), 1.81-2.05(2 \mathrm{H}, \mathrm{m}), 2.73-2.81(1 \mathrm{H}, \mathrm{m}), 3.80-3.84$ $(1 \mathrm{H}, \mathrm{m}), 8.02(3 \mathrm{H}, \mathrm{s}), 8.75(1 \mathrm{H}, \mathrm{d}, J=8.8 \mathrm{~Hz}) ;{ }^{13} \mathrm{C} \mathrm{NMR}$ (75.5 MHz, DMSO- $\left.d_{6}\right) 23.71,24.45,29.70,30.64,50.09$, 55.85, 124.26, 125.17, 130.47, 132.04, 138.42, 145.56, 166.52; HRMS-ESI $(m / z):[\mathrm{M}+\mathrm{Na}]^{+}$calcd for $\mathrm{C}_{13} \mathrm{H}_{14} \mathrm{Br}_{4} \mathrm{~N}_{2} \mathrm{NaO}_{4} \mathrm{~S}$, 636.7259; found, 636.7267 .

Synthesis of compound 7. The 2-sulfobenzoic anhydride 4, $\mathrm{R}^{1-4}=\mathrm{H}$ (1.102 mmol, $\left.300 \mathrm{mg}\right)$ was dissolved in $3 \mathrm{~mL}$ DCM. The mixture was cooled to $0{ }^{\circ} \mathrm{C}$, and compound 3 (1.102 mmol, $300 \mathrm{mg}$ ) was added in a mixture of $3 \mathrm{~mL} \mathrm{DCM}$ and $3 \mathrm{~mL}$ diethyl ether. The solution was soon clouded by white precipitate, and the suspension was stirred for $24 \mathrm{~h}$. The solvent was removed in vacuum, and the white solid was purified by column chromatography on silica gel (ethanol/DCM 1:1). Yield: $377 \mathrm{mg}, 75 \%$. Mp $249{ }^{\circ} \mathrm{C}$; IR (nujol) v: 2970, 2886, 1462, 1377, 1246, 1177, 820; ${ }^{1} \mathrm{H}$ NMR (300 MHz, $\left.\mathrm{CDCl}_{3}\right) 3.56(3 \mathrm{H}$, s), $3.68(3 \mathrm{H}, \mathrm{s}), 4.72-4.76(1 \mathrm{H}, \mathrm{d}, J=10.7 \mathrm{~Hz}), 5.76-5.79$ $(1 \mathrm{H}, \mathrm{m}), 6.29-6.32(2 \mathrm{H}, \mathrm{d}, J=7.9 \mathrm{~Hz}), 6.65-6.68(2 \mathrm{H}, \mathrm{d}, J=$ $8.3 \mathrm{~Hz}), 7.06-7.14(5 \mathrm{H}, \mathrm{m}), 7.16-7.37(2 \mathrm{H}, \mathrm{m}), 7.55-7.56$ $(1 \mathrm{H}, \mathrm{m}), 8.78-8.80(1 \mathrm{H}, \mathrm{d}, J=6.5 \mathrm{~Hz}) ;{ }^{13} \mathrm{C} \mathrm{NMR}(75.5 \mathrm{MHz}$, $\left.\mathrm{CDCl}_{3}\right)$ 54.93, 55.11, 56.06, 59.84, 113.79, 113.93, 125.55, $127.41,128.55,128.99,129.49,129.92,129.89,130.16,133.83$, 140.73, 158.94, 159.44, 169.08; HRMS-ESI $(m / z):[\mathrm{M}+\mathrm{Na}]^{+}$ calcd for $\mathrm{C}_{23} \mathrm{H}_{24} \mathrm{~N}_{2} \mathrm{NaO}_{6} \mathrm{~S}, 479.1247$; found, 479.1249 .

Synthesis of compound 8 . The 2-sulfobenzoic anhydride 4 , $\mathrm{R}^{1-4}=\mathrm{Br}(0.918 \mathrm{mmol}, 459 \mathrm{mg})$ was dissolved in a mixture of $3 \mathrm{~mL} \mathrm{DCM}$ and $3 \mathrm{~mL}$ THF. The solution was cooled to $0{ }^{\circ} \mathrm{C}$, and compound $3(0.918 \mathrm{mmol}, 250 \mathrm{mg})$ was added in a mixture of $3 \mathrm{~mL}$ DCM and $3 \mathrm{~mL}$ THF. The solution was soon clouded by grey precipitate, and the suspension was stirred for $24 \mathrm{~h}$. The solvent was removed in vacuum, and the grey solid was purified by column chromatography on silica gel (ethanol/DCM 1:1). Yield: $267 \mathrm{mg}, 38 \%$. Mp $304{ }^{\circ} \mathrm{C}$ (decomposition); IR (nujol) v: 2968, 2845, 2841, 1643, 1614, 1456, 1377, 1246, 
1039; ${ }^{1} \mathrm{H}$ NMR (300 MHz, DMSO- $\left.d_{6}\right) 3.64(3 \mathrm{H}, \mathrm{s}), 3.68(3 \mathrm{H}$, s), 4.50-4.53 (1H, d, $J=10.9 \mathrm{~Hz}), 5.41-5.47(1 \mathrm{H}, \mathrm{t}, J=$ $9.9 \mathrm{~Hz}), 6.68-6.71(2 \mathrm{H}, \mathrm{d}, J=8.2 \mathrm{~Hz}), 6.79-6.82(2 \mathrm{H}, \mathrm{d}, J=$ $8.3 \mathrm{~Hz}), 7.14-7.17(2 \mathrm{H}, \mathrm{d}, J=8.3 \mathrm{~Hz}), 7.32-7.34(2 \mathrm{H}, \mathrm{d}, J=$ $8.3 \mathrm{~Hz}), 8.48(3 \mathrm{H}, \mathrm{s}), 9.09-9.12(1 \mathrm{H}, \mathrm{d}, J=8.8 \mathrm{~Hz}) ;{ }^{13} \mathrm{C} \mathrm{NMR}$ (75.5 MHz, DMSO- $\left.d_{6}\right)$ 55.29, 55.51, 56.48, 59.96, 113.79, $114.21,124.19,125.21,126.84,129.36,129.89,130.42,138.27$, 145.59, 158.70, 159.67, 166.34; HRMS-ESI $(\mathrm{m} / \mathrm{z}):[\mathrm{M}+\mathrm{Na}]^{+}$ calcd for $\mathrm{C}_{13} \mathrm{H}_{18} \mathrm{~N}_{2} \mathrm{NaO}_{4} \mathrm{~S}, 794.7627$; found, 794.7630.

Addition of 4-hydroxycoumarin to $\boldsymbol{\alpha}, \boldsymbol{\beta}$-unsaturated ketones. The employed ligand 5-8 $(0.02 \mathrm{mmol})$ was dissolved in a $0.1 \mathrm{M}$ solution of alkali metal hydroxide in methanol $(0.2 \mathrm{~mL})$. The solution was evaporated, and the residue was dissolved in $0.5 \mathrm{~mL}$ solvent. $\alpha, \beta$-Unsaturated ketone $(0.14 \mathrm{mmol})$ was added subsequently, and the solution was stirred for $10 \mathrm{~min}$ at room temperature and cooled to the desired reaction temperature prior to the addition of 4-hydroxycoumarin. 4-Hydroxycumarin $(0.1 \mathrm{mmol}, 16 \mathrm{mg}$ ) was added, and the conversion was monitored by TLC. The mixture was subjected to column chromatography without quenching, and all yields were determined as isolated yields. The ee's were established by chiral HPLC according to racemic standards and literature data [23].

4-Hydroxy-3-(3-oxo-1-phenylbutyl)coumarin (warfarin). ${ }^{1} \mathrm{H}$ and ${ }^{13} \mathrm{C}$ NMR data were found to be in agreement with the literature data [23]. Chiral HPLC: The measurements were performed with an eluent consisting of $80 \%$ hexanes and $20 \%$ isopropanol on a Diacel Chiralpak AD-H column with $0.8 \mathrm{~mL} / \mathrm{min}$ flow. The detector wavelength was $254 \mathrm{~nm}$. $t_{\mathrm{R}}=10.1$ and $25.5 \mathrm{~min}$.

4-Hydroxy-3-(3-oxocyclohexyl)coumarin. ${ }^{1} \mathrm{H}$ and ${ }^{13} \mathrm{C}$ NMR data were found to be in agreement with the literature data [23]. Chiral HPLC: The measurements were performed with an eluent consisting of $80 \%$ hexanes and $20 \%$ isopropanol on a Diacel Chiralpak AD-H column with $0.8 \mathrm{~mL} / \mathrm{min}$ flow. The detector wavelength was $254 \mathrm{~nm} . t_{\mathrm{R}}=12.0 \mathrm{~min}$ (minor, $(S)$ enantiomer) and $13.3 \mathrm{~min}$ (major, $(R)$-enantiomer [23].

4-Hydroxy-3-(3-oxocycloheptyl)coumarin. ${ }^{1} \mathrm{H}$ and ${ }^{13} \mathrm{C}$ NMR data were found to be in agreement with the literature data [23] Chiral HPLC: The measurements were performed with an eluent consisting of $90 \%$ hexanes and $10 \%$ isopropanol on a Diacel Chiralpak AS-H column with $1.0 \mathrm{~mL} / \mathrm{min}$ flow. The detector wavelength was $210 \mathrm{~nm} . t_{\mathrm{R}}=22.5$ and $31.4 \mathrm{~min}$.

pH Measurements. The pH-range of the catalytic system was determined for the precatalyst $\mathbf{5}$ with lithium as Lewis acid. Conditions were chosen according to Table 1 , entry 3 , and the samples were prepared according to the procedure of catalysis. The solution of Li-5 in the specified solvent mixture was tested with wet universal $\mathrm{pH}$ indicator strips from Merck to give a $\mathrm{pH}$ of 9. After the addition of benzylideneacetone and stirring for $15 \mathrm{~min}$ at room temperature, the $\mathrm{pH}$ value was measured again to be 8-9. All measurements were repeated three times and three samples were prepared to give identical results.

Computational details. All theoretical calculations were performed with the program package TURBOMOLE-6.3 [34]. The employed density functionals were the nonempirical TPSSfunctional developed by Tao, Perdew, Scuseria and Staroverov [35] or the BP86-functional (as specified), combined with the contracted SVP basis set from Aldrich et al. [36]. The multipole accelerated resolution of identity approximation for two electron integral evaluation was used. All stationary points were fully optimized and confirmed by separate analytical frequency calculations. Transition structures were optimized with quasiNewton-Raphson methods by using the Powell-update algorithm for hessian matrix approximation (subsequent analytical frequency calculation). Absolute energies were zero-point corrected with the vibrational information received from harmonic analytical frequency calculations.

\section{Supporting Information}

\section{Supporting Information File 1}

Spectra of precatalysts and crystallographic data for compound $\mathbf{5}$.

[http://www.beilstein-journals.org/bjoc/content/ supplementary/1860-5397-9-18-S1.pdf]

\section{Acknowledgements}

We thank Eduard Maibach from the Merholz group for performing ESIMS measurements and evaluation of related data. We thank Lars Packschies and the RRZK for providing well furnished HPC systems for efficient quantum chemical calculations. We are grateful to the Fonds der Chemischen Industrie for financial support. We especially thank the Deutsche Forschungsgemeinschaft (DFG) for funding (GO-930/ 9-1) as well as the Bayer AG, the BASF AG, the Wacker AG, the Evonic AG, the Raschig GmbH, the Symrise GmbH, the Solvay $\mathrm{GmbH}$ and the OMG group for generous support.

\section{References}

1. Jiang, L.; Chen, Y.-C. Catal. Sci. Technol. 2011, 1, 354-365. doi:10.1039/c0cy00096e

2. Reisinger, C. M.; Wang, X.; List, B. Angew. Chem., Int. Ed. 2008, 47, 8112. doi:10.1002/anie. 200803238 
3. Gogoi, S.; Zhao, C.-G.; Ding, D. Org. Lett. 2009, 11, 2249. doi:10.1021/ol900538q

4. Jian, L.; Wu, H.; Wang, Y. Eur. J. Org. Chem. 2010, 2073. doi:10.1002/ejoc.200901227

5. Lu, X.; Liu, Y.; Sun, B.; Cindric, B.; Deng, L. J. Am. Chem. Soc. 2008, 130, 8134. doi:10.1021/ja802982h

6. Kateri Ahrendt, A.; Borths, C. J.; Mac Millan, D. W. C. J. Am. Chem. Soc. 2000, 122, 4243. doi:10.1021/ja000092s

7. Holub, N.; Jiang, H.; Paixão, M. W.; Tiberi, C.; Jørgensen, K. A. Chem.-Eur. J. 2010, 16, 4337. doi:10.1002/chem.200903274

8. Paixão, M. W.; Holub, N.; Vila, C.; Nielsen, M.; Jørgensen, K. A. Angew. Chem., Int. Ed. 2009, 48, 7338. doi:10.1002/anie.200903790

9. Zhong, C.; Shi, X. Eur. J. Org. Chem. 2010, 2999. doi:10.1002/ejoc.201000004

10. Zhou, J. Chem.-Asian J. 2010, 5, 422. doi:10.1002/asia.200900458

11. Simmons, B.; Walji, A. M.; MacMillan, D. W. C. Angew. Chem., Int. Ed. 2009, 48, 4349. doi:10.1002/anie.200900220

12. Sato, A.; Yoshida, M.; Hara, S. Chem. Commun. 2008, 6242. doi:10.1039/b814804j

13. Mukherjee, S.; List, B. J. Am. Chem. Soc. 2007, 129, 11336. doi:10.1021/ja074678r

14. Xu, Z.; Daka, P.; Budik, I.; Wang, H.; Bai, F.-Q.; Zhang, H.-X. Eur. J. Org. Chem. 2009, 4581. doi:10.1002/ejoc.200900678

15. Tsuji, J.; Minami, I.; Shimizu, I. Chem. Lett. 1983, 1325. doi:10.1246/cl.1983.1325

16. Trost, B. M.; Keinan, E. Tetrahedron Lett. 1980, 21, 2591. doi:10.1016/S0040-4039(00)92813-2

17. Bihelovic, F.; Matovic, R.; Vulovic, B.; Saicic, R. N. Org. Lett. 2007, 9 , 5063. doi:10.1021/ol7023554

18. Wong, W.; Li, H.; Wong, J. Org. Lett. 2005, 7, 1637-1639. doi:10.1021/ol0503337

19. Kristensten, T. E.; Vestli, K.; Hansen, F. K.; Hansen, T. Eur. J. Org. Chem. 2009, 5185. doi:10.1002/ejoc.200900664

20. Halland, N.; Hansen, T.; Jørgensen, K. A. Angew. Chem., Int. Ed. 2003, 42, 4955. doi:10.1002/anie.200352136

21. Xu, D.-Q.; Wang, Y.-F.; Zhang, W.; Luo, S.-P.; Zhong, A.-G.; Xia, A.-B.; Xu, Z. Y. Chem.-Eur. J. 2010, 16, 4177. doi:10.1002/chem.201000094

22. Dong, Z.; Wong, L.; Chen, X.; Liu, X.; Lin, L.; Feng, X. Eur. J. Org. Chem. 2009, 5192. doi:10.1002/ejoc.200900831

23. Zhu, X.; Lin, A.; Shi, Y.; Guo, J.; Zhu, C.; Cheng, Y. Org. Lett. 2011, 13, 4382. doi:10.1021/ol201715h

24. Xie, J.-W.; Yue, L.; Chen, W.; Du, W.; Zhu, J.; Deng, J.-G.; Chen, Y.-C. Org. Lett. 2007, 9, 413. doi:10.1021/ol062718a

25. Wang, J.-J.; Lao, J.-H.; Hu, Z.-P.; Lu, R.-J.; Nie, S.-Z. ARKIVOC 2010, No. ix, 229.

26. Rogozinska, M.; Adamkiewicz, A.; Mlynarski, J. Green Chem. 2011, 13, 1155. doi:10.1039/c1gc15118e

27. Xie, L.; Takeuchi, Y.; Cosentino, L. M.; Mc Phail, A. T.; Lee, K. H. J. Med. Chem. 2001, 44, 664. doi:10.1021/jm000070g

28. Visser, L. E.; van Schaik, R. H. N.; van Vliet, M.; Trienekens, P. H.; De Smet, P. A. G. M.; Vulto, A. G.; Hofmann, A.; van Duijn, C. M.; Stricker, B. H. C. Pharmacol. Ther. 2005, 77, 479. doi:10.1016/j.clpt.2005.02.009

29. Ufer, M. Clin. Pharmacokinet. 2005, 44, 1227. doi:10.2165/00003088-200544120-00003

30. Meinertz, T.; Kasper, W.; Kahl, C.; Jähnchen, E. B. J. Clin. Pharmacol. 1978, 5, 187. doi:10.1111/j.1365-2125.1978.tb01622.x

31. OReilly, R. A. N. Engl. J. Med. 1976, 295, 354. doi:10.1056/NEJM197608122950702

32. O'Reilly, R. A.; Levy, G. Pharmacol. Ther. 1978, 23, 212.
33. Allemann, C.; Gordillo, R.; Clemente, F. R.; Cheong, P. H.-Y.; Houk, K. N. Acc. Chem. Res. 2004, 37, 558. doi:10.1021/ar0300524

34. Ahlrichs, R.; Bär, M.; Häser, M.; Horn, H.; Kölmel, C. Chem. Phys. Lett. 1989, 162, 165. doi:10.1016/0009-2614(89)85118-8

35. Staroverov, V. N.; Scuseria, G. E.; Tao, J.; Perdew, J. P. J. Chem. Phys. 2003, 119, 12129. doi:10.1063/1.1626543

36. Schäfer, A.; Horn, H.; Ahlrichs, R. J. Chem. Phys. 1992, 97, 2571. doi:10.1063/1.463096

\section{License and Terms}

This is an Open Access article under the terms of the Creative Commons Attribution License

(http://creativecommons.org/licenses/by/2.0), which permits unrestricted use, distribution, and reproduction in any medium, provided the original work is properly cited.

The license is subject to the Beilstein Journal of Organic Chemistry terms and conditions: (http://www.beilstein-journals.org/bjoc)

The definitive version of this article is the electronic one which can be found at: doi:10.3762/bjoc. 9.18 